\title{
Comparative Review on the Cost-Effectiveness Analysis of Relief Teams' Deployment to Sudden-Onset Disasters
}

DOI:

10.1017/S1049023X19004540

\section{Document Version}

Accepted author manuscript

Link to publication record in Manchester Research Explorer

\section{Citation for published version (APA):}

Bartolucci, A., Walter, D., \& Redmond, AD. (2019). Comparative Review on the Cost-Effectiveness Analysis of Relief Teams' Deployment to Sudden-Onset Disasters. Prehospital and Disaster Medicine, 34(4), 415-421. https://doi.org/10.1017/S1049023X19004540

\section{Published in:}

Prehospital and Disaster Medicine

\section{Citing this paper}

Please note that where the full-text provided on Manchester Research Explorer is the Author Accepted Manuscript or Proof version this may differ from the final Published version. If citing, it is advised that you check and use the publisher's definitive version.

\section{General rights}

Copyright and moral rights for the publications made accessible in the Research Explorer are retained by the authors and/or other copyright owners and it is a condition of accessing publications that users recognise and abide by the legal requirements associated with these rights.

\section{Takedown policy}

If you believe that this document breaches copyright please refer to the University of Manchester's Takedown Procedures [http://man.ac.uk/04Y6Bo] or contact uml.scholarlycommunications@manchester.ac.uk providing relevant details, so we can investigate your claim.

\section{OPEN ACCESS}




\section{Prehospital and Disaster Medicine}

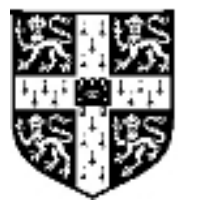

CAMBRIDGE
UNIVERSITY PRESS

\section{COMPARATIVE REVIEW ON THE COST-EFFECTIVENESS ANALYSIS OF RELIEF TEAMS DEPLOYMENT TO SUDDEN ONSET DISASTERS}

\begin{tabular}{|r|l|}
\hline Journal: & Prehospital and Disaster Medicine \\
\hline Manuscript ID & PDM-19-0023.R1 \\
\hline Manuscript Type: & Special Report \\
\hline Keywords: & $\begin{array}{l}\text { Comparative Review, Cost-Effectiveness Analysis, Relief teams, } \\
\text { Emergency Medical Team (EMT), Search And Rescue (SAR) }\end{array}$ \\
\hline \multicolumn{2}{|l}{} \\
\hline
\end{tabular}

\section{SCHOLARONE ${ }^{\mathrm{m}}$ \\ Manuscripts}




\section{ABSTRACT}

2 When a disaster exceeds the capacity of the affected country to cope with its own resources, the

3 provision of external rescue and health services is required, and the deployment of relief units

4 requested. Recently, the cost of international relief and the belief that such deployment is cost-

5 effective has been questioned by the international community; unfortunately, there is still little

6 informed debate and few detailed data are available. This paper presents the results of a

7 comparative review on the cost-effectiveness analysis of Search and Rescue (SAR) and

8 Emergency Medical Team (EMT) deployment. The aim of this work is to provide an overview of

9 the topic, highlights the criteria used to assess the effectiveness and identify gaps in existing

10 literature. The results show that both deployments are highly expensive, and their success is

11 strongly related to the time they need to be operational; SAR deployments are characterized by

12 limited outcomes in terms of lives saved, and EMTs by insufficient data and lack of detailed

13 assessment. This research highlights that the criteria used to assess the effectiveness need to be

14 explored further, considering different purposes, lengths of stay, and different activities

15 performed especially for any comparison. This study concludes that data reporting should be

16 mandatory for humanitarian response agencies.

18 KEYWORDS

19 Comparative Review, Cost-Effectiveness Analysis, Search and Rescue, Emergency Medical Team, 20 International Deployment 


\section{LIST OF ABBREVIATIONS}

$\begin{array}{lll}22 & \text { SAR } & \text { Search And Rescue } \\ 23 & \text { USAR } & \text { Urban Search And Rescue } \\ 24 & \text { EMT } & \text { Emergency Medical Team } \\ 25 & \text { NGO } & \text { Non-Governmental Organization } \\ 26 & \text { CEA } & \text { Cost-Effective Analysis } \\ 27 & \text { INSARAG } & \text { International SAR Advisory Group } \\ 28 & \text { FFH } & \text { Foreign Field Hospital } \\ 29 & \text { AMP } & \text { Advance Medical Post } \\ 30 & \text { FMT } & \text { Foreign Medical Team } \\ 31 & \text { WHO } & \text { World Health Organization } \\ 32 & \text { SOD } & \text { Sudden Onset Disaster } \\ 33 & \text { IEMT } & \text { International Emergency Medical Team }\end{array}$

34

\section{INTRODUCTION}

36 Natural disasters cause sudden health and social impacts upon populations with deaths and

37 injuries, damage to critical infrastructure, damage to health facilities, disruption of transportation

38 networks and of communication systems ${ }^{1,2}$. Earthquakes, in particular, are disasters that result in

39 the structural collapse of buildings which can entrap the occupants of the building ${ }^{3,4}$ under

40 complex, heavy structural debris, and rescue requires complex technical intervention.

41 Earthquakes often result in a massive need for medical care and health assistance; often

42 hospitals and health facilities are damaged or destroyed by the earthquake and are therefore not

43 able to adequately address health care needs due to the loss of functionality ${ }^{5}$.

44 When disasters exceed the capacity of the affected country to cope within its own resources,

45 assistance from external sources is required and typically requested ${ }^{6}$. The provision of

46 international disaster relief, including Search and Rescue (SAR) teams and Emergency Medical

47 Teams (EMTs) can be an essential support to the affected country. SAR activities involve the 
48 location, extrication, and initial medical treatment of victims trapped in structural collapse ${ }^{3}$. The

49 goal of SAR operations is to rescue the greatest number of trapped people in the shortest amount

50 of time, while minimizing the risk to rescuers ${ }^{7}$. EMTs are groups of health professionals

51 (doctors, nurses, paramedics etc.) coming from governments, militaries, charities (NGOs), and

52 international organizations whose goal is to provide treatment to patients affected by an

53 emergency or disaster.

54 Recently, the cost of international relief and the assumption that these deployments are cost-

55 effective have been questioned by many authors and agencies. De Ville de Goyet and colleagues

$56{ }^{8}$ commented that deploying a relief team to a disaster is an easy decision for donor countries and

57 it is usually a quick answer that meets an urgent need recognized by the donor public and media.

58 He continues by affirming that the international community is eager to demonstrate its solidarity,

59 exercise its "right of humanitarian intervention" and undertake its own relief effort on the basis

60 that local health services are unable or unwilling to respond adequately. This usually results in

61 large flows of teams and supplies that do not necessarily match the needs of the affected country

62 and potentially create problems with the coordination of the relief activities. Providing

63 humanitarian assistance is a highly emotional, and therefore political, undertaking but many

64 international agencies are starting to re-think the deployment strategy ${ }^{9}$.

65 Cost benefit analyses of SAR deployments exist but are rarely part of the decision process when

66 there is a need to save life. The acceptable costs for disaster response have rarely been

67 scientifically explored sufficiently even though this is crucial to real-world pre-disaster

68 preparedness and post-disaster response planning ${ }^{10}$. Despite the economic importance of this

69 subject, there is still little debate and published data. Most of the available information comes 
70 from general research and scientific analysis in different fields, each of them with a different 71 focus $^{4}$.

72 This paper presents the results of comparative review on the cost-effectiveness of SAR and EMT

73 deployment. A comparative scoping literature review was performed, selecting and summarizing

74 current knowledge from existing research papers and reports. Results of the search have been

75 used to map concepts and identify gaps in existing literature with the objective of suggesting

76 how to improve the evaluation of outcomes and inform the decision to deploy a relief team for

77 the future.

\section{METHODOLOGY}

80 A scoping literature review was carried out to provide an overview of the topic, highlights the

81 criteria used to assess the effectiveness and identify gaps in research related to relief teams'

82 deployment, searching, selecting and synthesizing existing knowledge. As described by Arksey

$83 \& \mathrm{O}^{\prime}$ Malley ${ }^{11}$, this methodology aims to: i) examine the extent, range, and nature of research

84 activity especially when is difficult to visualize the range of material that might be available; ii)

85 summarize and disseminate research findings to policy makers, practitioners, and consumers and

86 iii) identify gaps in the existing evidence base, followed by conclusions around the current

87 overall state of the research activity in the area.

88 The identification of researches from the scientific literature was performed through PubMed,

89 Scopus and Google Scholar search engines; Google Scholar, in particular, provides full texts of

90 scientific literature and research across different publishing formats ${ }^{12,13}$. For this paper, peer-

91 reviewed online academic journals and books, conference papers, theses and dissertations,

92 working documents, and technical reports from both national and international organizations 
93 were analysed. The review firstly involved a primary search using keywords followed by a grey

94 literature search; finally, a hand search was undertaken of the bibliographies of analyzed papers 95 (see Tab.1).

\section{INSERT TABLE 1 HERE}

99 To enrich the search, a discussion was undertaken with authors and stakeholders to acquire

100 further sources, references and insights; practitioners involved in the response to the Nepal

101 Earthquake in 2015 most recently involved and international responders were contacted.

102 The review was focused on English language literature, with references not written in English

103 excluded, using each of the following keywords: 1) Search and Rescue (SAR); 2) Cost-

104 Effectiveness Analysis (CEA); 3) cost; 4) International SAR Advisory Group (INSARAG); 5)

105 disaster and 6) Emergency Medical Team (EMT). Titles and documents containing those words,

106 or combinations of them, were reviewed to collect information about cost effectiveness of SAR

107 and EMT. With respect to the review of EMTs, the research was extended to consider the former

108 definitions of medical teams such as: 1) Foreign Field Hospital (FFH); 2) Advanced Medical

109 Post (AMP) and 3) Foreign Medical Team (FMT). Citations from the hand search have to be

110 complete while inaccurate references were not included. All publication dates were considered,

111 with special attention paid to papers published after the two WHO official classifications in 1998

112 for SAR and in 2013 for EMTs. Papers before those dates have been used to assess changes in

113 response and to evaluate improvement (for criteria of inclusion see Table 2).

114

INSERT TABLE 2 HERE 
117 Selected studies have been analyzed to gather information about costs and/or effectiveness of

118 SAR and/or EMT deployment, with special attention paid to works that provide a comparative

119 discussion on the cost-effectiveness in disaster, particularly Sudden Onset Disasters (SODs);

120 other deployments, such as conflicts, were not included.

121

122 RESULTS

123 A total of 7823 studies were found; 7769 records were excluded after reviewing the title and

124 duplicate removal. 54 records meeting the criteria were identified. 28 works met all the criteria

125 of the research on cost-effectiveness. Table 3 provides a list of the papers selected after the

126 review. 
INSERT TABLE 3 HERE

130 COST AND EFFECTIVENESS

131 SAR

132 Despite commonly beliefs, survivors in the immediate aftermath of a disaster react with

133 solidarity and tend help each other ${ }^{14-16}$. The first rescue efforts are usually performed by

134 survivors and by the local response assets $1,14,17-19$; the majority of survivors are found and

135 extricated quickly because they are usually "lightly trapped" 19,20 while a significant number of

136 earthquake victims remain "heavily" trapped under rubble requiring a heavy rescue response ${ }^{20}$.

137 According to Statheropoulos et al. ${ }^{21}$, SAR response is technically demanding and time

138 consuming; SAR success in operations, in fact, involves the advance purchase, operational

139 integration and deployment of best available technologies ${ }^{22}$ that makes the task-force highly

140 expensive.

141 Detailed information about USAR funding is not always available. According to the

142 Congressional Research Service ${ }^{9}$, the USA USAR task force, as part of the federal emergency

143 network response, was funded with US\$28 million in FY 2011 and US\$32.5 million in FY 2010.

144 This was due mostly to the perceived successful efforts in Haiti in early 2010 and the growing

145 support for a SAR team for domestic and international crisis. In the USA, a USAR team costs

146 between US\$1.8 - US\$2.2 million per year to maintain ${ }^{23}$. According to the Humanitarian

147 Emergency Response Review (HERR) ${ }^{24}$, the UK ISAR teams cost spent $£ 250,000$ per life saved

148 in Haiti, the UK surgical teams about one hundredth of this (a little over $£ 2,500$ ) per life saved.

149 The HERR suggests that there should be an intelligent deployment decision process. The UK's

150 main costs lie in maintaining equipment and personnel training at an effective readiness level 
151 with a 24/7 deployable capacity. The reported budget does not cover actual deployment costs,

152 which are met from separate government program funds for each specific response ${ }^{25}$. Neither

153 does the cost include the salary related costs of the UK Fire and Rescue Service personnel which

154 are met by their individual services.

155 Time is crucial in SAR operations; sophisticated and costly technology is required to minimize

156 the time to intervention and the sooner a victim is found, the higher the possibility for him/her to

157 survive ${ }^{4,20,22}$. SAR activities are effective when done in the first hours after an event and the

158 survival rate of trapped victims plunges dramatically over time ${ }^{26}$ and after several days of

159 searching, SAR teams typically find no additional survivors ${ }^{17}$.

160 As reported by Macintyre et al. ${ }^{20}$, the majority of rescues (90\%) occurr within the first 24 hours,

161 with the last survivor rescue usually four days post-impact. A dramatic drop-off occurs in during

162 the first 24-48 hour post-earthquake ${ }^{27}$. Rescue activities can last for days; according to

163 Macintyre et al. ${ }^{20}$, the average maximum time reported in their studies was 6.8 days with the

164 longest time to rescue of 19 days. Comparison between and the analysis of past events, the

165 Armenia earthquake in $1988^{19}$ and the Nepal Earthquake in $2015^{28}$ confirms that, despite

166 progressive improvement in coordination and better technologies, the effectiveness of SAR

167 teams has not increased.

168 Despite the significant cost associated with the deployment of an ISAR team, there is still a lack

169 of detailed information about the issues; for example, most of the existing data refer to a non-

170 itemized total budget, and most of the papers provide the total number of people extracted from

171 the rubble using the criteria "lives saved" rather than a distinction between people saved by

172 ISAR and those saved by locals. 
173 The debate around the effectiveness of SAR introduces a delicate ethical issue; despite the high 174 cost of their deployment, in most societies every possible effort is taken to save life ${ }^{20}$ and teams

175 are requested to operate until the last person has been saved. The risk of abandoning a potential

176 survivor deeply entrapped under rubble usually extends the activities of SAR many days after the

177 last "save" ${ }^{20}$. More, one of the most valuable service provided by highly-qualified urban search-

178 and-rescue teams is not necessarily finding survivors, but rather using the sophisticated structural

179 assessment, advanced search capabilities and specialized medical judgment to assist the local

180 leaders in limiting the period that focuses primarily on the possibility of trapped survivors. The

181 extension of this search phase has an impact on response priorities; as long as the possibility of

182 finding survivors exists, the response efforts and the attention of the affected community remain

183 focused on SAR even though this diverts efforts and resources away from the management of the

184 disaster and other post disaster issues ${ }^{20}$. This must be considered as part of the judgement

185 required from some who suggest that international urban search and rescue teams are never

186 needed since local personnel, using simple equipment, make the majority of earthquake rescues

187 within 24 hours ${ }^{29}$.

188 EMT

189 In the immediate aftermath of a disaster, authorities need to meet extraordinary treatment and

190 rehabilitation demands with resources that have been drained by the wider emergency response ${ }^{8}$.

191 Von Schreeb at al. ${ }^{30}$ reported the estimated cost per bed per day in US dollars during different

192 disasters, such as the Bam Earthquake (1750 US\$/bed/day) and the Kashmir earthquake (2250

193 US\$/bed/day).

194 As noticed by de Ville de Goyet ${ }^{8}$, the cost of mobilizing a field hospital for few weeks often

195 exceeds US\$1 million and suggests that the funds could be more productively used in the 
196 construction and equipping of simple but sturdy temporary facilities. In the case of the Bam

197 earthquake, the cost of rebuilding the entire primary and secondary health facilities and teaching

198 institution was estimated at around US\$10.5 million, the same spent on the dispatch of 12 field

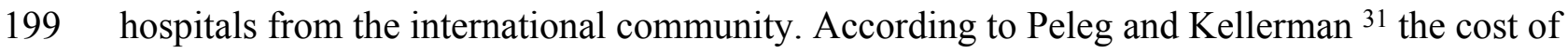

200 deploying a medium-size urban search and rescue mission is roughly equivalent to those of an

201 EMT type 1. The authors added that a heavy ISAR costs approximately US $\$ 900,000$ to deploy,

202 whilst the Israeli Defence Force spent US\$1.7 million on its EMT type 3 in Haiti.

203 As with SAR, EMT effectiveness is strongly dependent on the time of arrival. Aoki et al. ${ }^{10}$

204 analyzed 4,786 cases after the Kobe earthquake and found that $76.6 \%$ of those who lost their

205 lives died within an hour. Furthermore, they found that $36 \%$ of injured victims who died between

206 three and 12 hours after the earthquake might have been saved if the appropriate initial

207 emergency response had been available. Foreign mobile hospital and medical teams rarely arrive

208 promptly in the immediate aftermath of a disaster, usually not in time for immediate trauma care

209 1,2,32,33. De Ville de Goyet at al. ${ }^{8}$ also noticed that in Banda Aceh, Indonesia, after the 2004

210 tsunami, victims were eager to return to normality while external medical relief workers were

211 still arriving in large numbers.

212 The published literature suggests three days to be the average time for an EMT to arrive and

213 become operational into the affected country ${ }^{34}$. The challenge is not just to save the lives of the

214 trauma victims, but to re-establish a level of routine health care for a population living under

215 temporary shelters ${ }^{1}$. In the aftermath of a SOD historically, medical response has been focused

216 on providing emergency trauma care for the first 48 hours following the event, whilst they tend

217 to be operational much later and treat a different range of problems. The deployment of EMTs 
218 should perhaps be oriented toward supporting or substituting for a pre-existing but damaged

219 hospital or health facility rather than on providing immediate trauma care ${ }^{30}$.

220 As for SAR deployments, there is a lack of detailed published information about cost-

221 effectiveness of EMTs. In particular, the paucity of collection, management and reporting data

222 results in incomplete and largely qualitative research ${ }^{35}$. Most reports are narratives of the

223 activities performed by EMTs during recent disasters ${ }^{18,32}$, and few detail the cost and outcomes

$224{ }^{1,30}$. Many papers report the impossibility to describe the outcome of the EMT activities and the

225 tendency of facilities and agencies not to respond to request for detail on their activities ${ }^{33,36}$.

226 In addition, the literature usually reports only the total number of interventions ${ }^{36}$ making it

227 possible to create a timeline and define the phases of the medical response interventions. With

228 such lack of data, it is challenging to estimate and assess the outcome, the quality and potential

229 patient benefit for improvements from medical interventions. Gerdin et al. ${ }^{33}$ suggest that the

230 huge medical response to a disaster is inadequately documented and, despite the challenging

231 circumstances of their deployment, international agencies should be held accountable for the

232 services they provide.

233 Disasters are characterized by a highly emotional and sensationalized climate that has prevented

234 the adoption of a cost-effectiveness pragmatic approach to decision making ${ }^{8}$. When survival of

235 both people and political institutions are threatened, perceptions and visibility tend to prevail

236 over facts and analysis, resulting in a lack of evidence-based decision based upon cost/benefit

237 considerations.

238 The political benefit of sending an EMT should not be underestimated ${ }^{33}$ and usually there are

239 additional indirect drivers that trigger the deployment. After the Haiti earthquake, at least five 
240 (11\%) FFH stayed for a very short time, three for just a single week, and the cost effectiveness

241 and medical value of such a short intervention is debatable.

\section{DISCUSSION}

244 The analysis shows that both SAR and EMT deployment are very expensive and that the

245 effectiveness of both teams is strongly dependent upon the time of arrival. The value of SAR is

246 dependent upon the time of arrival before the maximum time of surviving; unfortunately, most

247 foreign rescue teams arrive late, when they travel over long distances, and their output in terms

248 of people saved remains low.

249 A similar argument is advanced for the EMTs that rarely arrives within $48 \mathrm{~h}$ and by which time

250 many patients will have already died from their injuries or been evacuated to other facilities. The

251 team focusing on immediate trauma care will arrive too late and find that they are caring for

252 relatively minor injuries and for health problems not directly related to the disaster. EMT

253 effectiveness is directly related to the ability to answer the needs of the population.

254 The literature on cost-effectiveness is based on an analysis of the ratio of lives saved divided by

255 cost of deployment. The concepts described in this paper show that there are consistent

256 differences, such as the different purpose, length of stay, and different activities performed, that

257 make the use of the same criterion to make a comparison between the two deployments too

258 simplistic. SAR, in fact, includes people extracted from the rubble, bodies recovered and

259 structural assessment, but it is difficult to quantify the effect simply on lives saved since this

260 outcome also requires local health system activity or the support of an EMT. On the other hand,

261 the assessment of the effectiveness of an EMT is more complicated; the role of the medical team

262 is not limited in time in the same way. They can stay longer but one of their primary functions is 
263 to support the local health system in providing wider medical care, particularly when the native

264 health system is heavily damaged. The criteria used to define effectiveness, particularly

265 considering their limitations, have been considered and found wanting. The researchers have

266 argued that there is a need to create a different way of considering cost-effectiveness. The

267 concept of comparison by "lives saved" is inappropriate; cost-effectiveness, the balancing of

268 spending on disaster resilience and the capacity building against post-incident response have

269 rarely been studied and compared, even though this plays a pivotal role in the ultimate outcome

270 from a disaster.

271 Specific data on outcomes from medical activities are rare, often incomplete and hard to analyze.

272 There is a need to agree a framework and core dataset for the assessment of medical

273 effectiveness, perhaps focusing on the number of people treated and the types of conditions

274 instead of the "lives saved".

275 Despite the importance of this topic, international discussion is still limited, and few data are 276 available to objectively describe the outcome of the presence of EMTs. Almost all the authors

277 from the search $1,17,19,23,30,33,36$ agree that this lack of appropriate information results in an

278 ineffective and wasteful relief response and, in the recent decades, not enough has been done to

279 improve preparedness and response programs based on lessons identified from reviewing

280 responses to previous earthquakes.

281 As De Ville De Goyet et al. ${ }^{8}$ report, the tendency of the international community to show

282 solidarity and exercise the "right of humanitarian intervention" often leads to mistakes and errors

283 in management. In many cases this is due to an underestimation of the local capacity to respond.

284 This error, with the accompanying disregard for the cost-effectiveness of the approach,

285 contributes to making disaster relief one of the least cost-effective health activities. As Glassey ${ }^{37}$ 
286 suggests, the cost of the deployment could save more lives if allocated pre-event to disaster risk

287 reduction and mitigation programs.

288 International humanitarian response of every type should be subject to post-assessment critical

289 analysis, including comparison between outcomes and costs, and using standardized and agreed

290 criteria. The evaluation should also consider different deployment approaches, including the

291 decision not to send a team for the immediate response or perhaps the deployment of a late and

292 differently skilled team with a focus on general medical care and rehabilitation rather than on

293 immediate trauma care.

294 Some of the literature presents proposals on how to improve the general effectiveness of

295 deployment and so, indirectly, cost. One common theme is to enhance the education and

296 resilience of local resources, with a focus on the first responders. Local and neighboring facilities

297 are the best placed to provide immediate health care ${ }^{1}$ and each improvement in coordination and

298 organizational capacity can be essential.

299 Local authorities and available resources, particularly neighboring hospital facilities, are

300 typically not sufficiently considered by international responding agencies, while building the

301 local coping capacity is one of the most cost-effective measures to improve the quality of the

302 national response and the external interventions ${ }^{1}$.

303 This study has some limitations; the authors selected the most relevant literature found but

304 limitations potentially exist due to the scarcity of directly relevant publications. Among the

305 works considered, only a few studies presented detailed costs, budget, organized dataset, and

306 evidence-based analysis.

307 Some concepts were only briefly explained within the papers and there is a potential

308 inconsistency in language complicating comparison. Some documents were narrative, qualitative 
309 research or were based upon interviews sector experts and after mission reports. Several authors

310 stressed the problem of data gathering with agencies rarely responding to requests to share data

$31133,35,36$.

\section{CONCLUSION}

314 The literature and evidence-based research analyses, showed that international SAR and EMT

315 deployments are very expensive. ISAR is characterized by few lives saved, largely due to the

316 response time, the long-distance travel and relatively late arrival in the disaster area. EMT

317 evaluation is hampered by a lack of detailed clinical information being gathered and made

318 available. Studies have demonstrated the difficulties in evaluating a response due to the lack of

319 reliable data and the tendency of responding agencies to not share internal reports and records.

320 Important lessons have been identified from previous disaster responses. The assumption that

321 receiving a great number of relief items always results in a more effective response is false;

322 humanitarian assistance should not be sent a priori, rather it should be the last option only where

323 the affected country does not have the capacity to absorb and recover itself. Before requesting

324 the deployment of an international team, the host nation and international community should

325 undertake a rapid assessment and assess the specific need. Local resources should be used, and

326 local response plans implemented, supported by the regional and international systems.

327 Increasing local adaptive and absorptive capacity is perhaps the most cost-effective way for the

328 affected Government to meet their responsibility.

329 This review has helped to identify specific research questions that need to be answered. Firstly,

330 the criteria for SAR and EMT cost-effectiveness assessment need to be improved to consider all

331 the outcomes of the two deployments. Secondly, this paper underlines the need to have a 
332 mandatory data recording strategy for all the agencies that take part in relief efforts and support 333 the concepts of cost-effectiveness and accountability.

334

\section{ACKNOWLEDGMENTS}

336 This study was funded by the Hong Kong Jockey Club (HKJC) within the collaborative project

337 "Training and Research Development for Emergency Medical Teams with reference to the WHO

338 Global EMTs initiative, classification and standards" between the Humanitarian Conflicts and

339 Response Institute (HCRI) and the Hong Kong Jockey Club Disaster Preparedness and Response

340 Institute (HKJCDPRI). 


\section{REFERENCES}

342 1. de Ville de Goyet C. Health lessons learned from the recent earthquakes and Tsunami in 343 Asia. Prehosp Disaster Med. 2007;22(1):15-21. doi:10.1017/S1049023X00004283.

344 2. Henderson AK, Lillibridge SR, Salinas C, Graves RW, Roth PB, Noji EK. Disaster

3. Cone DC. Rescue from the rubble: Urban search \&amp; rescue. Prehospital Emerg Care.

349 4. Morris B. Preparedness required for ensuring best coordinated use of international urban search and rescue assistance by earthquake affected countries. 2007.

351 5. Government of Nepal. Nepal Earthquake 2015: Post Disaster Needs Assessment. 2015:1134.

6. UNISDR. 2009 UNISDR Terminology on Disaster Risk Reduction. Int Strat Disaster Reduct. 2009:1-30. doi:978-600-6937-11-3.

355 7. OCHA. INSARAG Guidelines. 2016;I:26.

356 8. De Ville De Goyet C, Marti RZ, Osorio C. Natural Disaster Mitigation and Relief. Dis Control Priorities Dev Ctries. 2003;000(Ifrc):1147-1162.

358 9. Bea K. Urban Search and Rescue Task Forces: Facts and Issues. Growth (Lakeland). 3592010.

360 10. Aoki N, Nishimura A, Pretto EA, Sugimoto K, Beck JR, Fukui T. SURVIVAL AND 361 COST ANALYSIS OF FATALITIES OF THE KOBE EARTHQUAKE IN JAPAN. 362 Prehospital Emerg Care. 2004;8(2):217-222. doi:10.1080/312703004386.

363 11. Arksey H, O’Malley L. Scoping studies: towards a methodological framework. Int J Soc 
Res Methodol. 2005;8(1):19-32. doi:10.1080/1364557032000119616.

365 12. Tober M. PubMed, ScienceDirect, Scopus or Google Scholar - Which is the best search engine for an effective literature research in laser medicine? Med Laser Appl. 2011;26(3):139-144. doi:10.1016/j.mla.2011.05.006.

13. Mikki S. Google Scholar compared to Web of Science. A Literature Review. Nord J Inf Lit High Educ. 2009;1(1):41-51. doi:10.15845/noril.v1i1.10.

14. Auf der Heide E. The importance of evidence-based disaster planning. Ann Emerg Med. 2006;47(1):34-49. doi:10.1016/j.annemergmed.2005.05.009.

372 15. Quarantelli EL. Conventional Beliefs and Counterintuitive Realities. Soc Res (New York). 2008;75(3):873-905.

374 16. Bartolucci A, Magni M. Survivors' Solidarity and Attachment in the Immediate Aftermath 375 of the Typhoon Haiyan (Philippines). PLOS Curr Disasters. 2017. doi:10.1371/CURRENTS.DIS.2FBD11BD4C97D74FD07882A6D50EABF2.

377 17. Peleg K, Kellermann AL. Medical relief after earthquakes: It's time for a new paradigm. Ann Emerg Med. 2012;59(3):188-190. doi:10.1016/j.annemergmed.2011.07.028.

379 18. Abolghasemi H, Radfar MH, Khatami M, Nia MS, Amid A, Briggs SM. International 380 medical response to a natural disaster: lessons learned from the Bam earthquake $381 \quad$ experience. Prehosp Disaster Med. 2006;21(3):141-147.

382 19. Noji EK, Armenian HK, Oganessian A. Issues of rescue and medical care following the 1988 armenian earthquake. Int J Epidemiol. 1993;22(6):1070-1076. doi:10.1093/ije/22.6.1070.

20. Macintyre AG, Barbera J a, Smith ER. Surviving collapsed structure entrapment after earthquakes: a "time-to-rescue” analysis. Prehosp Disaster Med. 2006;21(1):4-17; 
discussion 18-9.

388 21. Statheropoulos M, Agapiou A, Pallis GC, et al. Factors that affect rescue time in urban 389 search and rescue (USAR) operations. Nat Hazards. 2015;75(1):57-69.

390 doi:10.1007/s11069-014-1304-3.

391 22. Statheropoulos M, Agapiou A, Pallis GC, et al. Factors that affect rescue time in urban 392 search and rescue (USAR) operations. Nat Hazards. 2015;75(1):57-69. doi:10.1007/s11069-014-1304-3.

394 23. Alexander D. The Costs of Relief in International Disasters. 2011:1-19.

395 24. Ashdown L (Paddy). Humanitarian Emergency Response Review. Humanit Emergencies. 2011;(March):58

397 25. DFID. United Kingdom International Search and Rescue (UK ISAR) Deployment Support Programme for Emergency Response Operations Overseas (2012 - 2015). 2015.

399 26. Bartels SA, Vanrooyen MJ. Medical complications associated with earthquakes. Lancet. 2012;379(9817):748-757. doi:10.1016/S0140-6736(11)60887-8.

401 27. Barbera JA, Cadoux CG. Search, rescue, and evacuation. Crit Care Clin. 1991;7(2):321$402 \quad 337$.

403 28. Okita Y, Katsube T. Coordination of International Urban Search and Rescue ( USAR )

404 Teams in the 2015 Nepal Earthquake : “ Disaster Literacy” for International USAR. $405 \quad 2016 ; 16(7): 24-36$.

406 29. de Ville de Goyet C. Stop propagating disaster myths. Aust J Emerg Manag.

$407 \quad$ 1999;14(4):26-28. doi:10.1016/S0140-6736(00)02642-8.

408 30. von Schreeb J, Riddez L, Samnegård H RH. Foreign field hospitals in the recent sudden409 onset disasters in Iran, Haiti, Indonesia, and Pakistan. Prehosp Disaster Med. 
2008;23(2):144-151; discussion 152-153. doi:10.1017/S1049023X00005768.

411 31. Peleg K, Kellermann AL. Medical Relief After Earthquakes : It' s Time for a New

412 Paradigm. YMEM. 2012;59(3):188-190. doi:10.1016/j.annemergmed.2011.07.028.

413 32. Care H, May JP, Joseph P, Pape JW, Binswanger IA. Early Disaster Response in Haiti:

414 The Israeli Field Hospital Experience. Ann Intern Med. 2010:391-393.

415 33. Gerdin M, Wladis A, von Schreeb J. Foreign field hospitals after the 2010 Haiti

416 earthquake: how good were we? Emerg Med J. 2012:1-6. doi:10.1136/emermed-2011-

417200717.

418 34. Arziman I. Field Organization and Disaster Medical Assistance Teams. Turkish J Emerg

419 Med. 2015;15(Supp 1):11-19. doi:10.5505/1304.7361.2015.79923.

420 35. Redmond AD, Mardel S, Taithe B, et al. A qualitative and quantitative study of the surgical and rehabilitation response to the earthquake in Haiti, January 2010. Prehosp

423 36. Brolin K, Hawajri O, von Schreeb J. Foreign medical teams in the philippines after typhoon haiyan 2013 - Who were they, when did they arrive and what did they do? PLoS Curr. 2015;7(DISASTERS):1-8. doi:10.1371/currents.dis.0cadd59590724486bffe9a0340b3e718.

427 37. Glassey S. Analysis of urban search and rescue markings applied following the 22 February 2011 Christchurch earthquake. J Search Rescue. 2013;1(1):29-49. 
TABLES

\begin{tabular}{|l|l|l|l|}
\hline Search Type & Source & $\begin{array}{l}\text { Publication } \\
\text { Dates }\end{array}$ & Search Terms \\
\hline Primary & $\begin{array}{l}\text { Google Scholar, Scopus, } \\
\text { PubMed }\end{array}$ & All & $\begin{array}{l}\text { SAR; CEA; cost; INSARAG; WHO; disaster; } \\
\text { EMT; FFH; FMT }\end{array}$ \\
\hline Grey & $\begin{array}{l}\text { DFID, HERR, WHO, } \\
\text { INSARAG, OCHA }\end{array}$ & All & $\begin{array}{l}\text { SAR; CEA; cost; INSARAG; WHO; disaster; } \\
\text { EMT; FFH; FMT }\end{array}$ \\
\hline Hand Searching & $\begin{array}{l}\text { Bibliographies from all } \\
\text { selected papers }\end{array}$ & All & $\mathrm{n} / \mathrm{a}$ \\
\hline
\end{tabular}

Table 1: Search type used to identify researches to be included in the study

433

\begin{tabular}{|l|l|}
\hline $\begin{array}{l}\text { Inclusion } \\
\text { Criterion }\end{array}$ & Details \\
\hline Language & References not written in English were not included \\
\hline Reference & $\begin{array}{l}\text { The citation from hand searching needed to be complete. Incomplete or inaccurate references } \\
\text { were not included }\end{array}$ \\
\hline Reference type & $\begin{array}{l}\text { Scientific literature, peer-reviewed online academic journals and books, conference papers, } \\
\text { theses and dissertations, working documents, technical reports from national and international } \\
\text { organizations }\end{array}$ \\
\hline Topic & $\begin{array}{l}\text { Studies must discuss costs and/or effectiveness of SAR and/or EMT deployment after disaster, } \\
\text { especially SODs. }\end{array}$ \\
\hline
\end{tabular}

Table 2: Details of the Inclusion Criteria Applied to Search Results 


\begin{tabular}{|c|c|c|c|c|c|c|c|}
\hline Citation & Type* & SAR & EMT & Costs & Effectiveness & Case study & Disaster \\
\hline Abolghasemi et al., 2006 & $\mathrm{R}$ & . & FFHs & . & $\mathrm{X}$ & Iran 2003 & EQ \\
\hline Alexander, 2011 & B & USAR & FFHs & $\mathrm{X}$ & $\mathrm{X}$ & Haiti 2010 & EQ \\
\hline Aoki et al., 2004 & $\mathrm{P}$ & . & EMS & $\mathrm{X}$ & $\mathrm{X}$ & Japan 1995 & EQ \\
\hline Arziman, 2015 & $\mathrm{Rv}$ & . & DMAT & $\mathrm{X}$ & $\mathrm{X}$ & . & . \\
\hline Bartels \& VanRooyen, 2011 & $\mathrm{Rv}$ & SAR & . & . & $\mathrm{X}$ & Various & EQ \\
\hline Bea, 2010 & $\mathrm{R}$ & USAR & . & . & $\mathrm{X}$ & USA & \\
\hline Brolin et al., 2015 & $\mathrm{P}$ & . & FMT & . & $\mathrm{X}$ & Philippines 2012 & Typhoon \\
\hline de Ville de Goyet et al., 2000 & A & . & FMT & $\mathrm{X}$ & $\mathrm{X}$ & . & . \\
\hline de Ville de Goyet et al., 2006 & $\mathrm{C}$ & SAR & $\mathrm{FH}$ & $\mathrm{X}$ & $\mathrm{X}$ & Indonesia 2004 & Tsunami \\
\hline de Ville de Goyet, 2006 & $\mathrm{R}$ & . & FFHs & X & $\mathrm{X}$ & Iran 2003; Asia 2004; Pakistan 2005 & $\begin{array}{c}\text { EQ, } \\
\text { Tsunami }\end{array}$ \\
\hline DFID, 2013 & $\mathrm{Rv}$ & ISAR & . & $\mathrm{x}$ & . & . & . \\
\hline DFID, 2015 & $\mathrm{bc}$ & ISAR & . & $\mathrm{X}$ & . & . & \\
\hline Gerdin et al., 2012 & $\mathrm{P}$ & . & FFHs & $\mathrm{X}$ & $\mathrm{X}$ & Haiti 2010 & EQ \\
\hline Glassey, 2013 & $\mathrm{P}$ & USAR & . & . & $\mathrm{X}$ & NZ 2011 & EQ \\
\hline Henderson et al., 1994 & $\mathrm{P}$ & . & DMAT & $\mathrm{X}$ & $\mathrm{X}$ & Hawaii 1992 & Hurricane \\
\hline HERR, 2011 & $\mathrm{R}$ & USAR & . & . & . & UK & . \\
\hline Kondo et al., 2010 & $\mathrm{P}$ & . & DMAT & . & $\mathrm{X}$ & Japan & EQ \\
\hline Kreiss et al., 2010 & $\mathrm{P}$ & . & FFHs & . & $\mathrm{X}$ & Haiti 2010 & EQ \\
\hline Macintyre et al., 2006 & $P$ & SAR & . & . & $\mathrm{X}$ & 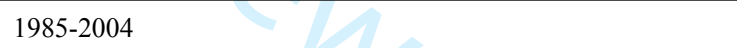 & EQ \\
\hline Morris, 2007 & $\mathrm{D}$ & SAR & . & $\mathrm{X}$ & $\mathrm{X}$ & +1 & \\
\hline Noji et al., 1993 & $\mathrm{P}$ & SAR & MC & . & $\mathrm{X}$ & Armenia 1998 & EQ \\
\hline Okita \& Katsube, 2016 & $\mathrm{R}$ & USAR & MT & - & $\mathrm{X}$ & Nepal 2015 & EQ \\
\hline Peleg \& Kellerman, 2012 & $\mathrm{P}$ & USAR & MT & $\mathrm{X}$ & $\mathrm{X}$ & Iran 2003; Indonesia 2009; Haiti 2010; NZ 2004; Pakistan 2005 & EQ \\
\hline Salman \& Gul, 2014 & $\mathrm{P}$ & . & $\mathrm{FH}$ & . & $\mathrm{X}$ & . & . \\
\hline Schnitzer \& Briggs & $\mathrm{P}$ & . & $\mathrm{FH}$ & . & . & Iran 2003 & EQ \\
\hline Statheropoulos et al., 2014 & $\mathrm{P}$ & USAR & . & $\mathrm{X}$ & $\mathrm{X}$ & Various & $\cdot$ \\
\hline von Schreeb et al., 2008 & $\mathrm{P}$ & . & FFHs & $\mathrm{X}$ & $\mathrm{X}$ & Iran 2003; Haiti 2004; Indonesia 2004; Pakistan 2005 & EQ \\
\hline WHO, 2017 & A & . & EMT & $\mathrm{X}$ & . & . & \\
\hline
\end{tabular}

